TRATAMENTO PRESERVATIVO DE BAMBUS ( $\left.{ }^{1}\right)$. A. Azzini (2), D. Ciaramello, F. P. Martins e H. J. Scaranari. Segundo Wein-Chin $\left({ }^{3}\right)$, existem mais de mil espécies de bambu espalhadas pelo mundo. No Brasil, as mais difundidas são Bambusa tuldoides, $B$. vulgaris, $B$. vulgaris var. vittata, Dendrocalamus giganteus e algumas espécies do gênero Phyllostachys, que são aquelas que apresentam rizomas do tipo monopodial.

A principal limitação no uso generalizado dos colmos de bambu no meio rural é sua baixa durabilidade natural, devido ao ataque de insetos furadores e fungos.

Galvão $\left({ }^{4}\right)$ salientou que medidas de ordem cultural, tais como colher colmos maduros no período seco do ano, diminuíram os ataques ocasionados pela broca-do-bambu.

De acordo com a crença popular, pode-se também evitar ou diminuir os ataques ocasionados pela broca, colhendo-se os colmos de bambu na fase minguante da Lua.

Simão ("), trabalhando com $B$. vulgaris, concluiu que as fases da Lua, relativamente à época do corte de colmos, não influíram de modo algum na vida útil dos mesmos. Apenas o tratamento com Thanalith melhorou as condições de conservação dos colmos, principalmente naqueles que foram divididos ao meio, longitudinalmente.

O objetivo deste trabalho foi verificar a eficiência de diversos produtos preservativos, na durabilidade dos colmos de quatro espécies de bambu, utilizados como moirões no suporte de videiras.

Material e métodos - Foram utilizados colmos com três anos de idade, representativos, quanto ao desenvolvimento médio, das espécies Bambusa vulgaris Schrad, Guadua angustifolia Kunth, Dendrocalamus giganteus Munro e $D$. strictus Nees, provenientes do Centro Experimental de Campinas, do Instituto Agronômico.

Dos colmos colhidos, utilizaram-se apenas as partes basais e medianas, que foram seccionados em moirões com aproximadamente dois metros de comprimento.

Os moirões receberam tratamento químico à base de creosoto, pentaclorofenol, Wolmanite CB e pentaclorofenato de sódio, na concentração de $5 \%$, com exceção do creosoto.

O tratamento com Wolmanite CB e pentaclorofenato de sódio foi pelo processo de substituição de seiva ou transpiração radial, conforme preconizou Galvão $\left({ }^{4}\right)$.

(1) Recebida para publicação em 23 de maio de 1977

(2) Com bolsa de suplementação do C.N.Pq.

$\left({ }^{3}\right)$ WEI-CHIN, L. The bamboo of Thailand - Taiwan Forestry Research Institute, 1968. 52 p. (Special Bulletin n. ${ }^{\circ}$ ).

(4) GALVĀo, A. P. M. Processos práticos para preservar a madeira. Piracicaba, ESALQ, USP, 1975. $29 \mathrm{p}$. (Tese).

(5) SIMÃO, S. Conservação do bambu. An. Esc. Agric. Queiroz 14-15:151-160, 1957-1958. 
As aplicações do creosoto e pentaclorofenol foram respectivamente pelos processos banho quente/frio e banho frio.

Os moirões, após os tratamentos preservativos, permaneceram enterrados no solo durante todo o período de execução do ensaio.

Resultados e conclusões No quadro 1 encontram-se os dados de durabilidade média dos moirões, nos 20 tratamentos estudados.

QUADRO 1. - Durabilidade média (em anos), de moirões de bambu de diversas espécies, que receberam diferentes tratamentos preservativos (*)

\begin{tabular}{|c|c|c|c|c|c|}
\hline \multirow{3}{*}{ Tratamento } & \multicolumn{5}{|c|}{ Espécie } \\
\hline & \multirow{2}{*}{$\begin{array}{c}\text { Bambusa } \\
\text { vulgaris }\end{array}$} & \multirow{2}{*}{$\begin{array}{c}\text { Guadua } \\
\text { angusti- } \\
\text { folia }\end{array}$} & \multicolumn{2}{|c|}{ Dendrocalamus } & \multirow{2}{*}{ Médias ** } \\
\hline & & & giganteus & strictus & \\
\hline Testemunha ... & 2,5 & 2,4 & 2,2 & 2,4 & $2,4 \mathrm{c}$ \\
\hline Creosoto $\ldots . . .$. & 4,0 & 3,8 & 4,0 & 4,0 & $4,0 \mathrm{a}$ \\
\hline Wolmanit CB .......... & 3,1 & 3,2 & 3,5 & 3,6 & $3,4 \mathrm{~b}$ \\
\hline Pentaclorofenol & 3,2 & 3,2 & 3,9 & 3,0 & $3,3 \mathrm{~b}$ \\
\hline Pentaclorofenato & & 2,5 & 2,5 & 2,5 & $2,5 \mathrm{c}$ \\
\hline de sódio $\ldots \ldots \ldots \ldots \ldots$ & 2,7 & & & & \\
\hline Médias & $\mathbf{3 , 1}$ & 3,0 & 3,2 & 3,1 & 3,1 \\
\hline
\end{tabular}

* Médias de três repetições

** Tukey $(5 \%)=0,36$

A análise da variância dos resultados obtidos (quadro 2 ) índica que apenas o tratamento com produtos preservativos aumentou significativamente a durabilidade média dos moirões, sendo o tratamento com creosoto superior aos demais, ao nível de $1 \%$ de probabilidade.

Observa-se também, no quadro 2, que as diferentes espécies de bambu, bem como a interação entre espécies e produtos preser- vativos, não influiram na vida útil dos moirões.

Dos resultados obtidos, conclui-se que os tratamentos à base de creosoto, Wolmanite CB e pentaclorofenol elevaram a durabilidade média dos moirões. 0 tratamento com creosoto foi o mais eficiente, seguindo-se os tratamentos com Wolmanite CB e pentaclorofenol, com resultados equivalentes. 
QUADRO 2. - Análise da variância dos dados do quadro 1

\begin{tabular}{|c|c|c|c|c|}
\hline Fonte de variação & GL & $\mathbf{S Q}$ & $\mathbf{Q M}$ & $F$ \\
\hline Repetições & 2 & 0,1730 & 0,0865 & $0,90 \mathrm{~ns}$ \\
\hline Tratamentos & (19) & 22,5188 & 1,1852 & $12,34 * *$ \\
\hline Espécies & 3 & 0,3323 & 0,1107 & $1,15 \mathrm{~ns}$ \\
\hline Produtos preservativos & 4 & 20,2334 & 5,0583 & $52,69 * *$ \\
\hline $\begin{array}{l}\text { Espécie } x \text { produto pre- } \\
\text { servativo }\end{array}$ & 12 & 1,9531 & 0,1627 & $1,69 \mathrm{~ns}$ \\
\hline Resíduo & 38 & 3,6489 & 0,0960 & 一 \\
\hline Total & 59 & 26,3407 & 0,0446 & - \\
\hline
\end{tabular}

$$
\begin{aligned}
\mathrm{s} & =0,3098 \\
\mathrm{x} & =3,1 \\
\mathrm{cv} & =10,0 \% \\
* * & \text { significativo ao nível de } 1 \% \text { de probabilidade } \\
\mathrm{ns} & =\text { não significativo }
\end{aligned}
$$

A aplicação de pentaclorofenato de sódio não altcrou a durabilidade natural dos moirões. SEÇÃO DE PLANTAS FIBROSAS
E ESTAÇÃO EXPERIMENTAL DE JUNDIAf, INSTITUTO AGRONOMICO DO ESTADO DE SÃO PAULO.

\section{PRESERVATIVE TREATMENT OF BAMBOO}

\section{SUMMARY}

It was compared the influence of creosote, Wolmanit CB, pentachlorinephenol, and sodium pentachlorinephenate in the durability of bamboo culms used as support of grape-vine, the following bamboo species being studied: Bambusa vulgaris Schrad, Guadua angustifolia Kunth, Dendrocalamus giganteus Munro, and D. strictus Nees.

The results showed that bamboo species didn't affect the durability of the culms: The treatment with creosote, Wolmanite CB, and pentachlorinephenol increased culms durability, meanwhile the treatment with creosote was the best. The treatment with wolmanit CB and with pentachlorinephenol were equivalent. On the other hand, the sodium pentachlorinephenate didn't affect the native durability of bamboo culms. 